\title{
Hydroxychloroquine-induced Hyperpigmentation of the Skin
}

AMR H. SAWALHA, MD, Division of Rheumatology, Department of Internal Medicine, and Computational Medicine and Bioinformatics, University of Michigan, Ann Arbor, Michigan, USA. Address correspondence to Dr. A.H. Sawalha, 5520 MSRB-1, SPC 5680, 1150 W. Medical Center Drive, Ann Arbor, Michigan 48109, USA. E-mail: asawalha@umich.edu. J Rheumatol 2015;42:135-6; doi:10.3899/jrheum.140995

Hydroxychloroquine (HCQ)-associated hyperpigmentation is uncommon, with onset ranging from 3 months to 22 years following the initiation of therapy ${ }^{1}$.

A 32-year-old woman presented with a 1.5-year history of symmetric polyarthritis, positive rheumatoid factor, and anticyclic citrullinated peptide antibody, without erosive joint changes. She had presented shortly after a Cesarean birth complicated by wound dehiscence and infection. She was diagnosed with rheumatoid arthritis, and treatment was initiated with HCQ $200 \mathrm{mg}$ twice daily, a dose based on her weight and height. Subsequent to the healing of her Cesarean birth incision and after a period of breast-feeding, she started receiving methotrexate $15 \mathrm{mg}$ weekly while continuing HCQ therapy. She presented 3 months later with multiple skin lesions predominantly on her neck, bilateral forearms, and dorsal feet. The skin lesions were macular or patchy, some well and others poorly demarcated, with a hyperpigmentation of gray to black discoloration, generally annular, but some with irregular morphology. They were flat without induration or scaling (Figure 1). A diagnosis of HCQ-associated hyperpigmentation was made, and HCQ was discontinued. The patient did not develop any new lesions and the existing lesions have slowly improved over the subsequent 4 months. A comprehensive eye examination did not show any evidence of retinopathy.

Mucocutaneous hyperpigmentation because of antimalarial therapy has been reported since World War $\mathrm{II}^{2}$; however, HCQ-associated hyperpigmentation seems to be less common than with other antimalarials such as chloroquine $^{3,4}$. The onset of HCQ-associated hyperpigmentation

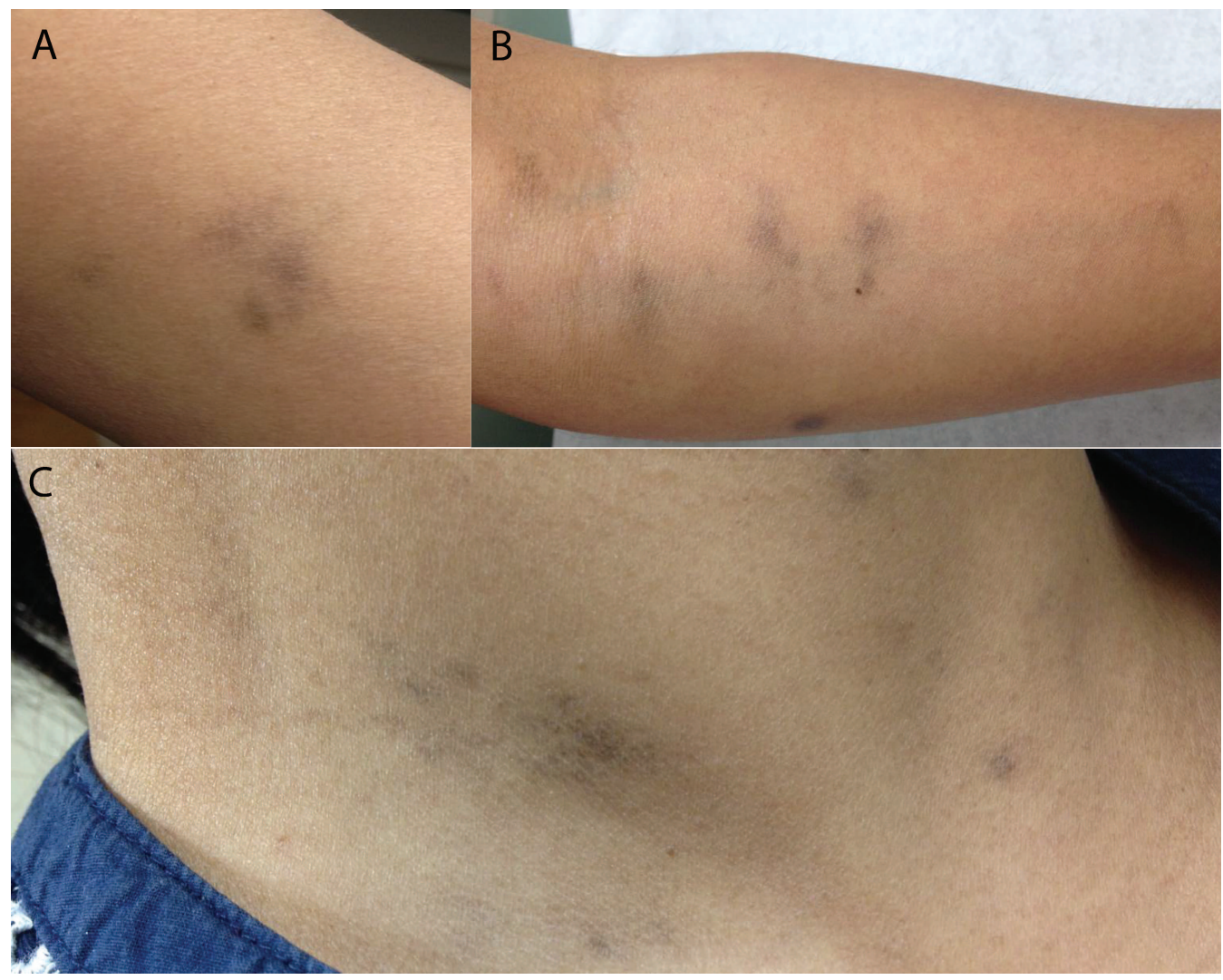

Figure 1. Hydroxychloroquine-associated hyperpigmentation with gray to black discoloration. 
ranges from 3 months to 22 years following the initiation of therapy, with a median of 6.1 years ${ }^{1}$. In our case, hyperpigmentation of the skin appeared about 1 year after initiating therapy. Treatment consisted of discontinuing HCQ, which led to the gradual decrease in hyperpigmentation of lesions within several months ${ }^{5,6}$. Although there is evidence that both melanin and iron deposits can be present within the dermis in hyperpigmented lesions induced by $\mathrm{HCQ}^{1}$, the exact mechanism of hyperpigmentation is unknown ${ }^{7}$. Further, the relationship between HCQ-associated hyperpigmentation and eye toxicity is not clear ${ }^{4}$; however, careful ophthalmological followup is certainly recommended ${ }^{7}$.

\section{REFERENCES}

1. Jallouli M, Frances C, Piette JC, Huong du LT, Moguelet P, Factor $\mathrm{C}$, et al. Hydroxychloroquine-induced pigmentation in patients with systemic lupus erythematosus: a case-control study. JAMA Dermatol 2013;149:935-40.
2. Lippard VW, Kauer GL Jr. Pigmentation of the palate and subungual tissues associated with suppressive quinacrine hydrochloride therapy. Am J Trop Med Hyg 1945;25:469-71.

3. Skare T, Ribeiro CF, Souza FH, Haendchen L, Jordão JM. Antimalarial cutaneous side effects: a study in 209 users. Cutan Ocul Toxicol 2011;30:45-9.

4. Mir A, Boyd KP, Meehan SA, McLellan B. Hydroxycholoroquine-induced hyperpigmentation. Dermatol Online J 2013;19:20723.

5. Rood MJ, Vermeer MH, Huizinga TW. Hyperpigmentation of the skin due to hydroxychloroquine. Scand J Rheumatol 2008;37:158

6. Amichai B, Gat A, Grunwald MH. Cutaneous hyperpigmentation during therapy with hydroxychloroquine. J Clin Rheumatol 2007; 13:113.

7. Tracy CL, Blakey B, Parker G, Roebuck J. Hydroxychloroquine-induced hyperpigmentation. J Clin Rheumatol 2013;19:292. 